\title{
Feasibility of Exercise Training in Cancer Patients Scheduled for Elective Gastrointestinal Surgery
}

\author{
Karin Valkenet $^{\mathrm{a}} \quad$ Jaap C.A. Trappenburg ${ }^{\mathrm{a}}$ Carlo C. Schippers ${ }^{\mathrm{b}}$ Lisa Wanders ${ }^{\mathrm{c}}$ \\ Lidwien Lemmens $^{d}$ Frank J.G. Backx ${ }^{a}$ Richard van Hillegersberg ${ }^{b}$ \\ ${ }^{a}$ Department of Rehabilitation, Nursing Science and Sports, and ${ }^{b}$ Department of Surgery, University Medical \\ Center Utrecht, Academic Hospital Utrecht, ' ${ }^{\circ}$ epartment of Human Nutrition, Wageningen University, and \\ ${ }^{\mathrm{d}}$ National Institute for Public Health and the Environment, Centre for Nutrition, Prevention and Health Services, \\ Utrecht, The Netherlands
}

\section{Key Words}

Preoperative exercise · Prehabilitation - Oncological surgery

\begin{abstract}
Background/Aims: This study examines the feasibility of a preoperative exercise program to improve the physical fitness of a patient before gastrointestinal surgery. Methods: An outpatient exercise program was developed to increase preoperative aerobic capacity, peripheral muscle endurance and respiratory muscle function in patients with pancreatic, liver, intestinal, gastric or esophageal cancer. During a consult at the outpatient clinic, patients were invited to participate in the exercise program when their surgery was not scheduled within 2 weeks. Results: The 115 participants followed on average 5.7 (3.5) training sessions. Adherence to the exercise program was high: $82 \%$ of the planned training sessions were attended, and no adverse events occurred. Mixed model analyses showed a significant increase of maximal inspiratory muscle strength $\left(84.1-104.7 \mathrm{~cm} \mathrm{H}_{2} \mathrm{O} ; \mathrm{p}=\right.$ 0.00 ) and inspiratory muscle endurance $\left(35.0-39.5 \mathrm{~cm} \mathrm{H}_{2} \mathrm{O}\right.$; $\mathrm{p}=0.00$ ). No significant changes were found in aerobic capacity and peripheral muscle strength. Conclusion: This exercise program in patients awaiting oncological surgery is
\end{abstract}

\section{KARGER}

E-Mail karger@karger.com www.karger.com/dsu

\section{(c) 2016 The Author(s) \\ Published by S. Karger AG, Basel 0253-4886/16/0335-0439\$39.50/0}

This article is licensed under the Creative Commons AttributionNonCommercial-NoDerivatives 4.0 International License (CC BYNC-ND) (http://www.karger.com/Services/OpenAccessLicense) Usage and distribution for commercial purposes as well as any distribution of modified material requires written permission. feasible in terms of participation and adherence. Inspiratory muscle function improved significantly as a result of inspiratory muscle training. The exercise program however failed to result in improved aerobic capacity and peripheral muscle strength, probably due to the limited number of training sessions as a result of the restricted time interval between screening and surgery.

(C) 2016 The Author(s) Published by S. Karger AG, Basel

\section{Introduction}

Surgical resection is the cornerstone of the curative treatment for gastrointestinal malignancies. Although postoperative outcomes have improved during the last decades as a result of the implementation of clinical pathways and improved surgical and anaesthesia techniques, there is still a substantial risk of postoperative complications. Besides the type of surgery, this risk is mainly determined by the preoperative status of the patient. In addition to age and comorbidities, several studies identify preoperative functional performance as an important predictor of postoperative outcome [1-4]. Functional limitations and inadequate activity levels are associated 
with worse postoperative outcomes, and this highlights the importance of good preoperative physical fitness of patients awaiting a major invasive operation like gastrointestinal surgery [1-5].

To decrease the risk of unwanted postoperative outcomes, optimising the health status of a patient before (oncological) surgery is increasingly regarded as an important part of the preoperative treatment process [6-9]. Optimising functional performance by an exercise program before a major invasive surgical procedure is called prehabilitation. Improved preoperative physical performance and health status may put a patient in a more favourable position to withstand the surgical stress [1013].

Inspiratory muscle training (IMT) is an example of a prehabilitation modality. IMT improves ventilatory capacity by increasing inspiratory (mainly diaphragm) muscle strength and endurance, which may prevent the imbalance between ventilatory demand and ventilatory capacity provoked by surgery [14]. IMT should not be confused with incentive spirometry and has shown to decrease postoperative pulmonary complications in several studies and is therefore regarded as a promising prehabilitation intervention [15-18]. Research on prehabilitation programs aimed at improving the overall exercise capacity and muscle strength before surgery is less common. Only a few pilot studies have investigated the effect of an exercise program before oncological surgery $[9,19]$. For this reason, a preoperative exercise program was designed to improve the physical status of patients scheduled for gastrointestinal oncological surgery. This study examined the feasibility of this exercise program and its effectiveness on improving physical fitness.

\section{Materials and Methods}

\section{Participants and Study Design}

The exercise program was designed for patients diagnosed with pancreatic, liver, intestinal, gastric or esophageal cancer who were scheduled for oncological surgery at the University Medical Center Utrecht. All patients were planned for surgery with curative intent, and the patients with gastric or esophageal cancer received perioperative chemotherapy treatment [20]. When the indication for surgery was given, patients were seen by a nurse practitioner at the outpatient clinic where they were educated about optimizing preoperative physical status regarding postoperative recovery. When the surgery was not scheduled within 2 weeks, patients were invited to undergo health status measurements and were asked to participate in the supervised outpatient exercise program. Patients who agreed to participate in the exercise program started the exercise program preferably within one week of consultation with the nurse practitioner.

\section{Exercise Program}

The participants of the exercise program followed 2 group training sessions a week at the outpatient clinic under supervision of a physiotherapist. The aim of the preoperative exercise program was to increase aerobic capacity, peripheral muscle endurance and respiratory muscle function. One training session consisted of 2 sessions of 20-30 min each on a stationary bike, a cross trainer or a row-ergometer. Training intensity was set at $60-85 \%$ of the maximal heart rate reserve calculated with the formula of Karvonen et al. [21]. To increase peripheral muscle endurance, the physical rehabilitation training (PRT) systems method was used [22]. The PRT method consists of 7 systems $(\mathrm{A}-\mathrm{F})$ in which the training load is the lowest in system A (aerobic endurance training) and the highest in system F (maximal strength training). Resistance training started with PRT-system B (3 series of 20-25 repetitions, 6090 s rest in between) followed by the PRT-system C ( 3 series of 13-20 repetitions, 90-120 s rest between series). Both systems are aimed at improving aerobic muscle endurance. The exercises consisted of leg press, bench press, lateral pull down, back extension and abdominal flexion exercises.

Alongside the exercise program, participants were instructed to start IMT at home to improve inspiratory muscle function. IMT is performed with an inspiratory muscle trainer (Threshold IMT, Respironics New Jersey, USA), which increases the inspiratory load. The load of this device (range 9-41 $\mathrm{cm} \mathrm{H}_{2} \mathrm{O}$ ) can be adjusted manually. Patients had to breathe in and out through the inspiratory muscle trainer for 20 min daily starting at an inspiratory resistance of $30 \%$ of their maximal inspiratory pressure (MIP) [16]. When the rate of the perceived exertion after a training session was below 5 (range $0-10$ ), patients increased the training load by $5 \%$ [16]. Participants were instructed to report their training parameters in a daily training log. IMT progress was evaluated weekly during one of the training sessions by the physiotherapist by assessing inspiratory muscle function. Furthermore, training load was adjusted when indicated. Additionally, participants were advised to perform 30 min of moderately intensive physical activities at least at 5 days a week according to the WHO and Dutch Health Enhancing Physical Activity guidelines [23].

\section{Health Status Measurements}

Demographic and anthropometric variables that were collected at baseline included age, gender, weight, height, tumor location, type of surgery and ASA (American Society of Anesthesiologists) classification [24]. During the consultation with the nurse practitioner, all patients (participants and non-participants) were asked to undergo several non-invasive baseline measurements to assess contraindications for training, fatigue, quality of life (QoL), aerobic capacity, peripheral muscle strength and respiratory muscle function. For the participants of the exercise program, aerobic capacity, peripheral and respiratory muscle function follow-up measurements were planned weekly during one of the group training sessions.

Physical Activity Readiness, Fatigue and QoL

To identify patients for whom physical training might be contraindicated, the self-administered Physical Activity Readiness Questionnaire was used [25]. The number of times a question was answered positive was recorded, with a maximal possible score of 7. In case of one or more positive answers, the nurse practitioner was contacted to discuss if a patient could participate in the exercise program. 
The Fatigue Severity Scale (FSS) was used to assess the level of perceived fatigue and its impact on daily life and activities. A higher score correlates with higher levels of fatigue. The minimum score is 9; the maximum score is 63 [26]. A cut-off value of 42 has been reported in cancer patients to indicate severe fatigue [27].

QoL was assessed using the RAND-36 and the EORTC QLQ-30 questionnaires. The RAND-36 consists of 36 questions that are grouped into 8 domains. Two summary scores can be derived from the domain scores: the Physical Component Summary (PCS) and Mental Component Summary (MCS) measures [28]. The EORTC QLQ-30 is an integrated system for assessing the health-related QoL of cancer patients and includes 5 functional scales, 3 symptom scales, a global health status scale, and 6 single items. In both questionnaires, a higher score correlates with better QoL (range 0-100).

\section{Aerobic Capacity}

The Åstrand test is a submaximal exercise test, providing an indirect estimation of the maximal oxygen consumption $\left(\mathrm{VO}_{2} \mathrm{max}\right)$, which can be taken as an indicator for aerobic capacity [29]. Prior to each test, heart rate, blood pressure and saturation at rest were measured. Patients started pedaling on the ergometer for $6 \mathrm{~min}$ with a frequency of 50 rounds per minute. The workload (Watt) was determined by the physiotherapist based on an estimated fitness level of the patient. Heart rate was recorded every minute. The average heart rate between 5 and 6 min was considered the mean steady state value and used to estimate $\mathrm{VO}_{2} \mathrm{max}(\mathrm{ml} / \mathrm{kg} / \mathrm{min})$ using the Astrand nomogram [30].

\section{General Muscle Strength}

To evaluate peripheral muscle function, handgrip strength, elbow flexion strength and knee extension strength were assessed. Three consecutive measurements were carried out for each muscle group on each side, with standardized verbal encouragement. The mean value for all measurements per muscle group was used in the analyses. Handgrip strength was assessed with a handheld dynamometer (JAMAR, USA) which has shown high test-retest reliability and has been recommended for clinical use [31,32]. The elbow flexion and knee extension strength measurements were carried out using a microFET-2 handheld dynamometer (Hoggan Health Industries, USA) according to the 'make' technique, a valid and reliable method to measure maximal isometric contraction $[33,34]$.

\section{Inspiratory Muscle Function}

For the evaluation of inspiratory muscle strength, MIP was measured with the microRPM hand-held respiratory pressure meter (MircoMedical, USA). Five successive measurements were taken and the maximum difference allowed between the measurements was $10 \%$. The highest value obtained was recorded as MIP$\max [35]$.

The incremental inspiratory muscle endurance was tested starting at a resistance of $30 \%$ of the MIP, which was then increased by $8 \%$ every minute. The maximum resistance that could be tolerated for $1 \mathrm{~min}$ (MIP-endurance) was used to calculate the incremental inspiratory muscle endurance ((MIP-endurance/MIP$\left.\max )^{*} 100\right)$.

\section{Feasibility Outcomes}

Baseline characteristics, including the health status measurements described above, were compared between participants and non-participants to check for sampling bias. To determine the fea- sibility of the program, several indicators were evaluated. The percentage of patients that agreed on following the training and the reasons for non-participation were recorded. During the exercise program, adherence to the group training sessions and reasons for non-attendance were recorded. Furthermore, adverse events reported by patients participating in the exercise program were documented.

\section{Effectiveness of the Training Program}

To evaluate whether the exercise program actually met the goal of increasing preoperative physical fitness, the aerobic capacity, peripheral muscle strength and inspiratory muscle function of the participants were measured weekly during the exercise program.

\section{Analysis}

Descriptive statistics were used to analyze the demographic and measurement variables at baseline. Summary statistics are presented as numbers with percentages in the case of categorical variables and as means with SDs in the case of continuous variables. The baseline variables were tested for between-group differences with an independent samples t test or chi-square test.

The repeated measures performed in the participants of aerobic capacity, peripheral muscle strength and inspiratory muscle function were analyzed using mixed models with random intercept and random slope. The covariates gender, age and tumor location were entered in the mixed models. Participants and non-participants could not be compared for the follow-up measurements, since non-participants underwent measurements only at baseline.

\section{Results}

Between July 2006 and April 2008, approximately 310 patients underwent pancreatic, liver, intestinal, gastric or esophageal cancer surgery. After the outpatient consult, 168 patients underwent the health status measurements, of which 115 participated in the exercise program (fig. 1).

\section{Baseline Variables}

Baseline characteristics of the participants and nonparticipants are summarized in table 1 . No information is available of the patients that did not undergo the health status assessment. Based on the ASA classification scores, participants had less severe systemic disease compared to the non-participants $(\mathrm{p}=0.04)$ and the tumor location was not evenly divided across both groups $(\mathrm{p}=0.02)$. Patients were comparable for the health status measurements.

The mean FSS score in both groups fell below the cutoff value of 42 points for severe fatigue [27]. The mean reported EORTC scores in both groups (66.7 and 65.6) were higher than the reference values of cancer patients (61.3) [36] and the mean RAND-36 scores PCS (40.3 and 41.1) and MCS (39.0 and 39.8) were lower compared to the Dutch references values of the general population of 


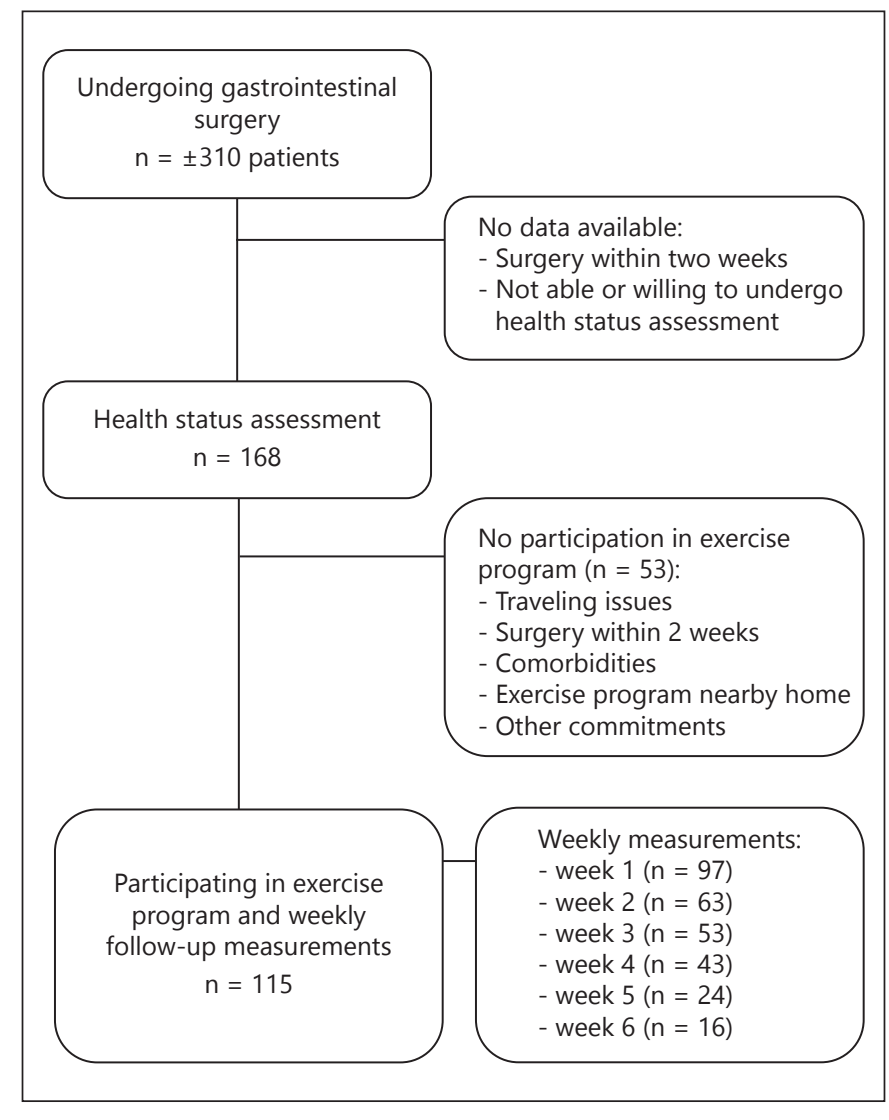

Fig. 1. Flowchart of recruitment and performed measurements.

56-65 years (46.8 and 50.7, respectively) [28] indicating decreased QoL in both groups.

Although not statistically different, the travel distance for the non-participants was longer $(39.1 \mathrm{~km})$ than that of the participants $(25.7 \mathrm{~km})$.

\section{Feasibility}

Of all patients undergoing gastrointestinal surgery, $168(54 \%)$ underwent the health status assessment and of those $115(37 \%)$ participated in the exercise program. The main reasons for not participating in the exercise program were related to the transport: traveling distance $(\mathrm{n}=$ 18 ) and no transport $(n=3)$. Other reasons for non-participation were: surgery within 2 weeks $(n=3)$, other commitments $(n=3)$, comorbidities $(n=2)$, prefer exercise program nearby their home $(\mathrm{n}=2)$. In the participants, the mean (SD) number of days between the invitation for the exercise program and the first training session was 6.3 (5.8). The average number of days between the first training session and surgery was 30.9 (19.4). On average, 5.7 (3.5) training sessions were attended and 1.2
(1.6) training sessions were missed. Of the participants, 56 (48\%) did not miss a single session. Of the 844 scheduled training sessions, 694 were attended, resulting in an overall training adherence of $82 \%$. The main reasons for missing a session were other appointments at the hospital (26.5\%) and (public) holidays (25.3\%). No adverse events were reported during the training sessions.

\section{Effectiveness of the Exercise Program}

The participants underwent weekly measurements of their aerobic capacity, general muscle strength and inspiratory muscle function. The time courses of these measurements (with 95\% CIs) are displayed in figures 2 and 3 . The mixed model analyses showed a significant increase of the mean estimates over time from weeks 1 to 6 of MIP-max (84.1-104.7 $\left.\mathrm{cm} \mathrm{H}_{2} \mathrm{O} ; \mathrm{p}=0.00\right)$ and MIPendurance (35.0-39.5 $\left.\mathrm{cm} \mathrm{H}_{2} \mathrm{O} ; \mathrm{p}=0.00\right)$. A ceiling effect was observed for MIP-endurance since increasingly more patients reached the maximum load of the threshold device of $41 \mathrm{~cm} \mathrm{H}_{2} \mathrm{O}$ during this test $(54 \%$ at the first time point up to $95 \%$ at the last time point). This is also illustrated by the decreasing ratio of MIP-endurance/MIPmax in figure 2 .

No significant changes over time were found in aerobic capacity $(28.5-29.0 \mathrm{ml} / \mathrm{kg} / \mathrm{min} ; \mathrm{p}=0.12)$, handgrip strength (34.7-35.7 kg; $\mathrm{p}=0.26)$ and knee extension strength (261.6-282.9 Newton; $\mathrm{p}=0.11)$. The elbow flexion strength showed a non-significant increase from the weeks 1 to 5 (173.2-179.9 Newton; $\mathrm{p}=0.08)$ and a significant decrease between weeks 5 and 6 (166.1 Newton; $\mathrm{p}=0.04)$.

\section{Discussion}

The aim of this study was to investigate the feasibility of a preoperative exercise program and its effects on preoperative physical fitness in patients undergoing gastrointestinal oncological surgery. Adherence to the exercise program was high and no adverse events occurred during the program. Due to the short interval between screening and surgery, the number of training sessions attended was low. The exercise program did result in increased inspiratory muscle function but failed to result in increased peripheral muscle strength and aerobic capacity.

\section{Feasibility}

The exercise program is highly feasible in terms of adherence to the training sessions and the training itself. The training adherence of $82 \%$ and the legitimate reasons 
Table 1. Baseline values

\begin{tabular}{|c|c|c|c|c|c|}
\hline Patient characteristics & $\mathrm{n}$ & $\begin{array}{l}\text { Non-participants } \\
(\mathrm{n}=53)\end{array}$ & $\mathrm{n}$ & $\begin{array}{l}\text { Participants } \\
(\mathrm{n}=115)\end{array}$ & $\begin{array}{l}\mathrm{p} \text { value } \\
(2 \text {-sided })\end{array}$ \\
\hline Age, years, mean (SD) & 53 & $65.6(11.8)$ & 115 & $62.3(10.7)$ & 0.74 \\
\hline Male, n (\%) & 53 & $32(60.4)$ & 115 & $66(57.4)$ & 0.72 \\
\hline Height, m, mean (SD) & 53 & $172.4(10.3)$ & 115 & $172.0(12.8)$ & 0.91 \\
\hline Weight, kg, mean (SD) & 53 & $76.7(16.5)$ & 115 & $77.3(14.9)$ & 0.70 \\
\hline $\mathrm{BMI}, \mathrm{kg} / \mathrm{m}^{2}$, mean (SD) & 53 & $25.7(4.6)$ & 115 & $26.6(9.5)$ & 0.46 \\
\hline Tumor location, n (\%) & 53 & & 115 & & 0.02 \\
\hline Pancreas & & $9(17)$ & & $16(13.9)$ & \\
\hline Liver & & $9(17)$ & & $28(24.4)$ & \\
\hline Colon & & $22(41.5)$ & & $27(23.5)$ & \\
\hline Esophagus & & $6(11.3)$ & & $35(30.4)$ & \\
\hline Stomach & & $7(13.2)$ & & $9(7.8)$ & \\
\hline ASA physical status classification, $\mathrm{n}(\%)$ & 53 & & 115 & & 0.04 \\
\hline I & & $8(15.1)$ & & $38(33.0)$ & \\
\hline II & & $36(67.9)$ & & $65(56.5)$ & \\
\hline III & & $9(17.0)$ & & $12(10.4)$ & \\
\hline Travel distance, km, mean (SD) & 53 & $39.1(26.1)$ & 115 & $25.7(15.8)$ & 0.65 \\
\hline \multicolumn{6}{|l|}{ Health status measurements } \\
\hline PARQ score, $\mathrm{n}(\%)$ & 48 & & 112 & & 0.66 \\
\hline 0 & & $18(37.5)$ & & $38(33.9)$ & \\
\hline$\geq 1$ & & $30(62.5)$ & & $74(66.1)$ & \\
\hline \multicolumn{6}{|l|}{ Inspiratory muscle function, mean (SD) } \\
\hline MIP-max, $\mathrm{cm} \mathrm{H}_{2} \mathrm{O}$ & 44 & $68.2(28.7)$ & 97 & $75.6(29.5)$ & 0.13 \\
\hline MIP-endurance, $\mathrm{cm} \mathrm{H}_{2} \mathrm{O}$ & 33 & $34.3(7.9)$ & 80 & $35.2(7.9)$ & 0.59 \\
\hline MIP-end/MIP-max, $\%$ & 33 & $42.2(8.3)$ & 80 & $44.3(11.1)$ & 0.35 \\
\hline Astrand, $\mathrm{ml} / \mathrm{kg} / \mathrm{min}$, mean (SD) & 5 & NR & 44 & $28.5(6.5)$ & - \\
\hline Handgrip strength, kg, mean (SD) & 24 & $38.5(11.6)$ & 72 & $35.6(10.5)$ & 0.26 \\
\hline Elbow flexion strength, n, mean (SD) & 24 & $183.7(55.8)$ & 73 & $179.2(57.1)$ & 0.73 \\
\hline Knee extension strength, $n$, mean (SD) & 24 & $267.7(71.2)$ & 70 & $275.4(80.8)$ & 0.68 \\
\hline FSS score, mean (SD) & 21 & $35.2(14.7)$ & 75 & $30.5(13.6)$ & 0.17 \\
\hline RAND-36, mean (SD) & 24 & & 66 & & 0.49 \\
\hline PCS & & $40.3(6.4)$ & & $41.1(6.7)$ & \\
\hline MCS & & $39.0(9.1)$ & & $39.8(7.6)$ & \\
\hline EORTC, mean (SD) & 20 & & 54 & & 0.85 \\
\hline Global health status & & $66.7(24.5)$ & & $65.6(21.2)$ & \\
\hline
\end{tabular}

$\mathrm{BMI}=$ Body mass index; $\mathrm{PARQ}=$ physical activity readiness $\mathrm{NR}=$ not reported due to high volume of missing values.

for missing sessions show that participants were highly motivated to attend the training sessions. No adverse events were reported and all participants stated that they would participate again.

Of around $46 \%$ of patients undergoing gastrointestinal surgery, no health status data are available. A majority of these patients were not invited to the exercise program and the accompanying health status assessment, since their surgery was planned within 2 weeks. The overall participation was therefore $37 \%$, which is fairly low. However, of the patients eligible for the exercise program based on the available time until surgery, $68 \%$ participated in the exercise program. A participation rate of $68 \%$ is reasonable, since other preoperative training studies report lower participation rates [19, 37]. Having to travel to the outpatient hospital clinic twice a week was the most frequently reported reason for non-participation, which is in line with an earlier reported pilot study [19].

We compared the baseline and health status data of the participants with the non-participants to check for selection bias, since selection bias can decrease external valid- 


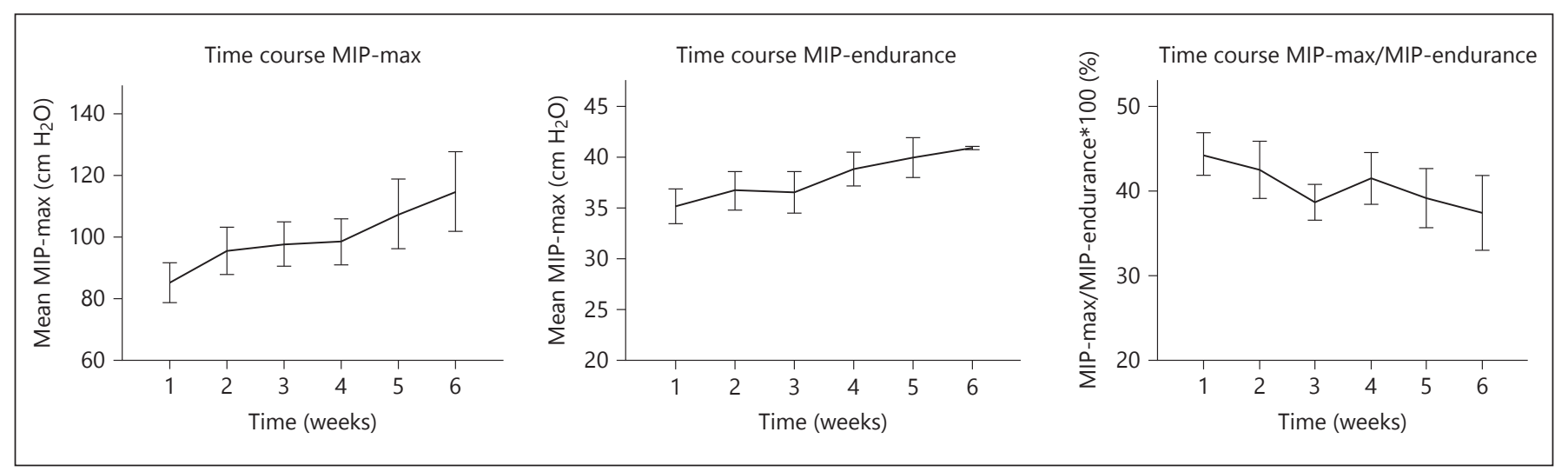

Fig. 2. Time courses of the inspiratory muscle function.
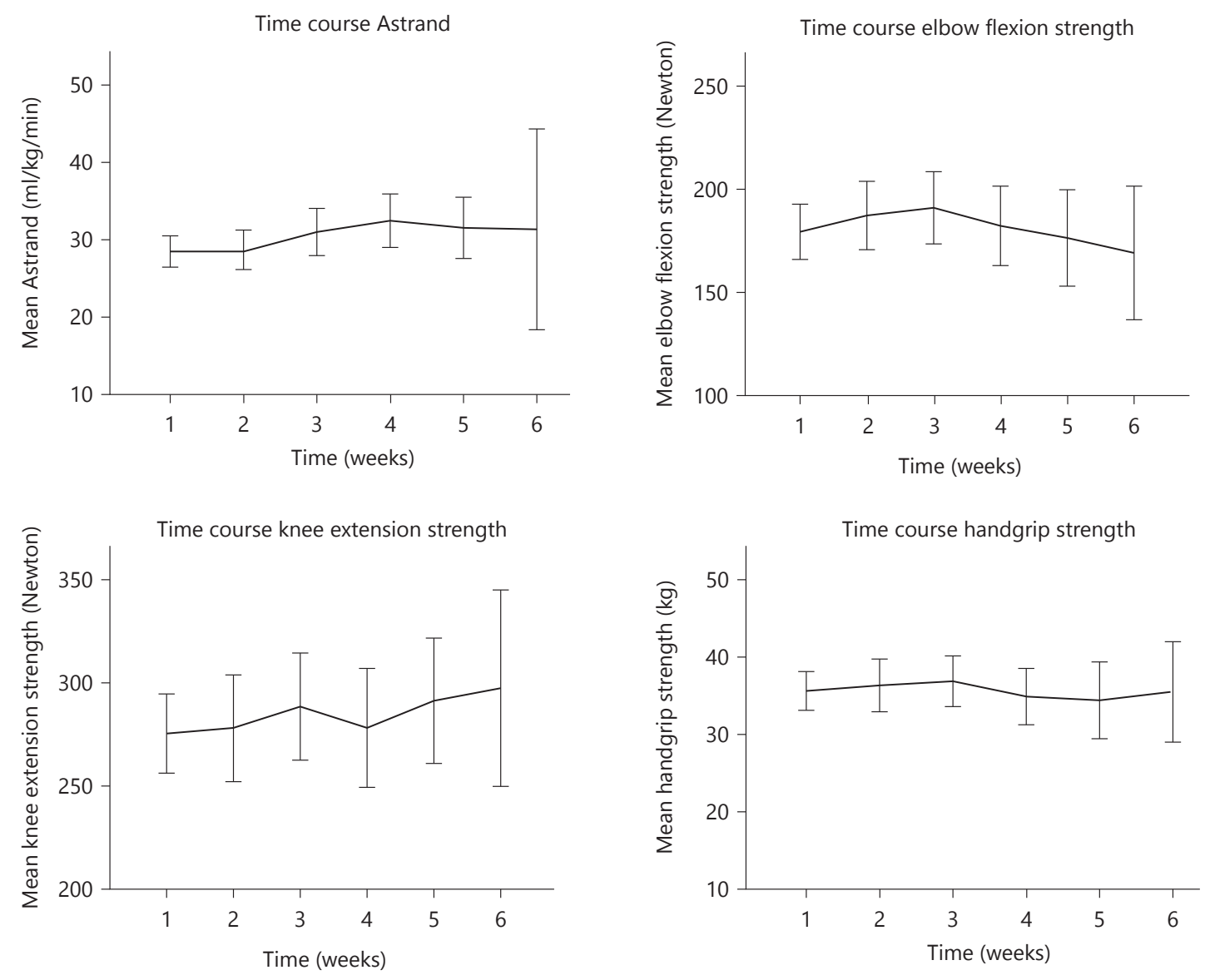

Fig. 3. Time courses of the aerobic capacity and peripheral muscle strength. 
ity. For example, it is possible that those interested in following an exercise intervention have a better health status, since they are more likely to be undertaking sports and exercise activities in general. Our results, however, do no confirm this hypothesis, since the scores of participants and non-participants were comparable in terms of the health status measurements at baseline. The feasibility based on the number of followed training sessions was moderate. Participants followed on average 5.7 training sessions. Preferably, patients would have followed more training sessions, but the interval between the first consultation and the date of surgery did not allow a longer intervention period.

\section{Effectiveness of the Exercise Program}

Our results show that inspiratory muscle strength improved significantly during the intervention period. This is in line with earlier studies that show that IMT can improve inspiratory muscle strength and endurance after 2 weeks of training in patients undergoing major invasive surgery $[16,38,39]$. Baseline values and the average increase of $20 \%$ of MIP-max are also comparable to the results in these studies. In our study, IMT was performed with a threshold device with a range of 9-41 $\mathrm{cm} \mathrm{H}_{2} \mathrm{O}$. Patients reported that they reached the maximum load of the training device before the end of their training period, which is confirmed by the ceiling effect reported during the endurance measurements because with time, an increasing number of patients reached a maximum score of $41 \mathrm{~cm} \mathrm{H}_{2} \mathrm{O}$. Therefore, the training load was suboptimal and this might have impaired the effects of this training.

No significant improvements were found in aerobic capacity, handgrip strength, knee extension strength and elbow flexion strength. Knee extension strength improved by $7 \%$, which is in line with an earlier pilot study that did find a significant increase in overall muscle strength and aerobic capacity [19]. Patients in the pilot study followed 9 training sessions (median), while our participants on average took part in 5 or 6 training sessions. Studies have found that the optimal conditions to achieve physiological adaptations are exercise programs of 3 months with 3 sessions a week [40-42]. Training programs of 12-18 weeks in cancer survivors have been shown to be successful in improving muscle strength and aerobic capacity $[43,44]$. Therefore, presumably our training period was too short to establish physiological adaptations. Another explanation of the lack in aerobic and musculoskeletal progress might be the training intensity. Currently, increasingly more evidence is available

Exercise Training in Cancer Patients for Elective Gastrointestinal Surger that supports the effectiveness of high intensity training [44-46]. A recent commentary investigated the available literature on the key principles of exercise training (frequency, intensity, time, type and progression) in the light of developing a consensus on the design of prehabilitation programs. Their overall conclusion is that individually prescribed and supervised high-intensity interval training is an effective form of exercise therapy prior to surgery [47]. Our program consisted of cardiorespiratory endurance training and low-load muscle endurance training. Although the physiotherapist consistently observed progress in the weight lifted and the number of repetitions performed by the participants, the training load might have been too low to result in increased general muscle strength in the available time period for the exercise program.

\section{Strengths and Limitations}

This study is one of the first studies to investigate the feasibility of exercise training in cancer patients awaiting gastrointestinal surgery. When this study was designed in 2005 , the general idea was that it was not feasible to train cancer patients. This study proves otherwise. The high number of participants, the high percentage of followed training sessions, and the absence of adverse events during training shows that exercise training before gastrointestinal surgery is possible and feasible. The high number of performed measurements during the exercise program is a big strength of this data and made it possible to investigate the time course of several functional measurements and the effect of the exercise program on these outcomes.

One major downfall of the study is the limited number of followed training sessions by the participants, which likely inhibited the effects of the exercise program on physical fitness.

Another limitation of our data is the amount of missing data in the aerobic capacity and muscle function measurements. About $40-50 \%$ of these measurements were missing and it is unclear whether or not this data are missing (completely) at random. When data are not missing at random, this is a violation of the assumptions for using multiple imputations. To avoid a reduced sample size by using standard repeated measure techniques, we chose to analyze the time course of the aerobic capacity and the muscle function measurements with a mixed models analysis. This multilevel approach has been proven to be a useful method to study changes over time in studies with missing data and this method gives unbiased estimates, makes it possible to include covariates and takes 
into account the dependency between different measurements within a patient [48]. Our data were collected between the years 2006 and 2008 and therefore, current management of oncological surgery patients might have changed. We however believe that our data are still valid nowadays since changes in management of oncological surgery patients mainly involves surgical and postoperative procedures, which do not affect the effectiveness of a preoperative exercise program on preoperative outcomes. Since the design of our training program a decade ago, only a few reports were published on prehabilitation and therefore, we believe this data are still very relevant and can help in the design of future prehabilitation programs.

\section{Recommendations}

The current available evidence does not allow the postponement a planned operation in cancer patients in order to complete a prehabilitation program. Therefore, to be able to investigate the effectiveness of a preoperative exercise program on postoperative outcomes and to draw solid conclusions, future scientific efforts are needed to define the most optimal balance of training intensity and frequency in the short time interval between diagnosis and surgery. To achieve physiological adaptations in a short time period, an exercise program incorporated in the preoperative period needs to be effective and time-efficient. A recent commentary and lit- erature summary concluded that high-intensity interval training is an effective form of exercise therapy prior to surgery and therefore we recommend future studies to investigate the effect of a high-intensity exercise program with a higher number of training sessions per week [47]. Furthermore, since travel distance and means of transport were the most frequently mentioned reasons for not participating, offering patients a training program nearby their home should be considered to increase participation numbers. Since IMT proved effective in improving inspiratory muscle function in the available time period, the effectiveness of this training on postoperative outcome is currently being investigated in esophagectomy patients in an international randomized controlled multicenter trial [7].

\section{Conclusions}

This preoperative exercise program in patients awaiting oncological surgery is feasible in terms of participation and adherence. Presumably due to the short intervention period, the exercise program failed to significantly increase preoperative peripheral muscle strength and aerobic capacity. The exercise program successfully improved the inspiratory muscle function, providing an opportunity to improve the preoperative pulmonary status of patients undergoing cancer surgery.

\section{References}

1 Arozullah AM, Khuri SF, Henderson WG, Daley J: Development and validation of a multifactorial risk index for predicting postoperative pneumonia after major noncardiac surgery. Ann Intern Med 2001;135:847857.

2 Fukuse T, Satoda N, Hijiya K, Fujinaga T: Importance of a comprehensive geriatric assessment in prediction of complications following thoracic surgery in elderly patients. Chest 2005; $127: 886-891$

-3 Lingard EA, Katz JN, Wright EA, Sledge CB Predicting the outcome of total knee arthroplasty. J Bone Joint Surg Am 2004;86-A:21792186.

-4 Dronkers JJ, Chorus AM, van Meeteren NL, Hopman-Rock M: The association of pre-operative physical fitness and physical activity with outcome after scheduled major abdominal surgery. Anaesthesia 2013;68:67-73.

5 Saxton A, Velanovich V: Preoperative frailty and quality of life as predictors of postoperative complications. Ann Surg 2011;253:12231229.
Hoogeboom TJ, Dronkers JJ, Hulzebos EH, van Meeteren NL: Merits of exercise therapy before and after major surgery. Curr Opin Anaesthesiol 2014;27:161-166.

7 Valkenet K, Trappenburg JC, Gosselink R, Sosef MN, Willms J, Rosman C, Pieters H, Scheepers JJ, de Heus SC, Reynolds JV, et al: Preoperative inspiratory muscle training to prevent postoperative pulmonary complications in patients undergoing esophageal resection (PREPARE study): study protocol for a randomized controlled trial. Trials 2014;15: 144.

8 Straatman J, Cuesta MA, de Lange-de Klerk ES, van der Peet DL: Hospital cost-analysis of complications after major abdominal surgery. Dig Surg 2015;32:150-156.

-9 Dronkers JJ, Lamberts H, Reutelingsperger IM, Naber RH, Dronkers-Landman CM, Veldman A, van Meeteren NL: Preoperative therapeutic programme for elderly patients scheduled for elective abdominal oncological surgery: a randomized controlled pilot study. Clin Rehabil 2010;24:614-622.
10 Courtney MD, Edwards HE, Chang AM, Parker AW, Finlayson K, Bradbury C, Nielsen $\mathrm{Z}$ : Improved functional ability and independence in activities of daily living for older adults at high risk of hospital readmission: a randomized controlled trial. J Eval Clin Pract 2012;18:128-134.

11 Topp R, Ditmyer M, King K, Doherty K, Hornyak J 3rd: The effect of bed rest and potential of prehabilitation on patients in the intensive care unit. AACN Clin Issues 2002;13: 263-276.

12 Dronkers JJ, Valkenet K: Prehabilitation: exercise therapy before major surgery; in Stam HJ, Buyruk HM, Melvin JL, Stucki G (eds): Acute Medical Rehabilitation, ed 1, 2012.

13 Hulzebos EH, van Meeteren NL: Making the elderly fit for surgery. Br J Surg 2016;103:e12e15.

14 Shekleton ME: Respiratory muscle conditioning and the work of breathing: a critical balance in the weaning patient. AACN Clin Issues Crit Care Nurs 1991;2:405-414. 
15 Dronkers J, Veldman A, Hoberg E, van der Waal C, van Meeteren N: Prevention of pulmonary complications after upper abdominal surgery by preoperative intensive inspiratory muscle training: a randomized controlled pilot study. Clin Rehabil 2008;22:134-142.

-16 Hulzebos EH, Helders PJ, Favié NJ, De Bie RA, Brutel de la Riviere A, Van Meeteren NL: Preoperative intensive inspiratory muscle training to prevent postoperative pulmonary complications in high-risk patients undergoing CABG surgery: a randomized clinical trial. JAMA 2006;296:1851-1857.

17 Valkenet K, van de Port IG, Dronkers JJ, de Vries WR, Lindeman E, Backx FJ: The effects of preoperative exercise therapy on postoperative outcome: a systematic review. Clin Rehabil 2011;25:99-111.

18 Valkenet K, de heer F, Backx FJ, Trappenburg JC, Hulzebos EH, Kwant S, van Herwerden LA, van de Port IG: Effect of inspiratory muscle training before cardiac surgery in routine care. Phys Ther 2013;93:611-619.

-19 Timmerman H, de Groot JF, Hulzebos HJ, de Knikker R, Kerkkamp HE, van Meeteren NL: Feasibility and preliminary effectiveness of preoperative therapeutic exercise in patients with cancer: a pragmatic study. Physiother Theory Pract 2011;27:117-124.

20 Cunningham D, Allum WH, Stenning SP, Thompson JN, Van de Velde CJ, Nicolson M, Scarffe JH, Lofts FJ, Falk SJ, Iveson TJ, et al: Perioperative chemotherapy versus surgery alone for resectable gastroesophageal cancer. N Engl J Med 2006;355:11-20.

21 Karvonen MJ, Kentala E, Mustala O: The effects of training on heart rate; a longitudinal study. Ann Med Exp Biol Fenn 1957;35:307315.

22 van Wingerden: Physical Rehabilitation Training, 2015.

23 Kemper HGC, Ooijendijk WTM, Stiggelbout $\mathrm{M}$ : Consensus over de nederlandse norm voor gezond bewegen. Tijdschr Soc Gezondheidsz 2000;78:180-183.

-24 Wolters U, Wolf T, Stützer H, Schröder T: ASA classification and perioperative variables as predictors of postoperative outcome. $\mathrm{Br} \mathrm{J}$ Anaesth 1996;77:217-222.

25 Thomas S, Reading J, Shephard RJ: Revision of the physical activity readiness questionnaire (PAR-Q). Can J Sport Sci 1992;17:338345.

-26 Krupp LB, LaRocca NG, Muir-Nash J, Steinberg AD: The fatigue severity scale. Application to patients with multiple sclerosis and systemic lupus erythematosus. Arch Neurol 1989;46:1121-1123.
27 Stone P, Richards M, A'Hern R, Hardy J: A study to investigate the prevalence, severity and correlates of fatigue among patients with cancer in comparison with a control group of volunteers without cancer. Ann Oncol 2000; 11:561-567.

28 Aaronson NK, Muller M, Cohen PD, EssinkBot ML, Fekkes M, Sanderman R, Sprangers MA, te Velde A, Verrips E: Translation, validation, and norming of the Dutch language version of the SF-36 health survey in community and chronic disease populations. J Clin Epidemiol 1998;51:1055-1068.

29 Noonan V, Dean E: Submaximal exercise testing: clinical application and interpretation. Phys Ther 2000;80:782-807.

30 Astrand PO, Ryhming I: A nomogram for calculation of aerobic capacity (physical fitness) from pulse rate during sub-maximal work. J Appl Physiol 1954;7:218-221.

-31 Shechtman O, Mann WC, Justiss MD, Tomita M: Grip strength in the frail elderly. Am J Phys Med Rehabil 2004;83:819-826.

32 Bohannon RW, Bubela DJ, Magasi SR, Gershon RC: Relative reliability of three objective tests of limb muscle strength. Isokinet Exerc Sci 2011;19:10.3233/IES-2011-0400.

33 Schaubert KL, Bohannon RW: Reliability and validity of three strength measures obtained from community-dwelling elderly persons. J Strength Cond Res 2005; 19:717-720.

34 Wang CY, Olson SL, Protas EJ: Test-retest strength reliability: hand-held dynamometry in community-dwelling elderly fallers. Arch Phys Med Rehabil 2002;83:811-815.

35 American Thoracic Society/European Respiratory Society: ATS/ERS statement on respiratory muscle testing. Am J Respir Crit Care Med 2002;166:518-624.

36 Scott NW, Fayers PM, Aaronson NK, Bottomley A, de Graeff A, Groenvold M, Gundy C, Koller M, Petersen MA, Sprangers MA: EORTC QLQ-C30 Reference Values, 2008.

37 Mayo NE, Feldman L, Scott S, Zavorsky G, Kim do J, Charlebois P, Stein B, Carli F: Impact of preoperative change in physical function on postoperative recovery: argument supporting prehabilitation for colorectal surgery. Surgery 2011;150:505-514.

38 Dettling DS, van der Schaaf M, Blom RL, Nollet F, Busch OR, van Berge Henegouwen MI: Feasibility and effectiveness of pre-operative inspiratory muscle training in patients undergoing oesophagectomy: a pilot study. Physiother Res Int 2013;18:16-26.

39 van Adrichem EJ, Meulenbroek RL, Plukker JT, Groen H, van Weert E: Comparison of two preoperative inspiratory muscle training pro- grams to prevent pulmonary complications in patients undergoing esophagectomy: a randomized controlled pilot study. Ann Surg Oncol 2014;21:2353-2360.

40 Iwasaki K, Zhang R, Zuckerman JH, Levine $\mathrm{BD}$ : Dose-response relationship of the cardiovascular adaptation to endurance training in healthy adults: how much training for what benefit? J Appl Physiol (1985) 2003;95:15751583.

41 Schjerve IE, Tyldum GA, Tjønna AE, Stølen T, Loennechen JP, Hansen HE, Haram PM, Heinrich G, Bye A, Najjar SM, et al: Both aerobic endurance and strength training programmes improve cardiovascular health in obese adults. Clin Sci (Lond) 2008;115:283293.

42 Wisløff U, Støylen A, Loennechen JP, Bruvold M, Rognmo O, Haram PM, Tjønna AE, Helgerud J, Slordahl SA, Lee SJ, et al: Superior cardiovascular effect of aerobic interval training versus moderate continuous training in heart failure patients: a randomized study. Circulation 2007;115:3086-3094.

43 De Backer IC, Vreugdenhil G, Nijziel MR, Kester AD, van Breda E, Schep G: Long-term follow-up after cancer rehabilitation using high-intensity resistance training: persistent improvement of physical performance and quality of life. Br J Cancer 2008;99:30-36.

-44 De Backer IC, Van Breda E, Vreugdenhil A, Nijziel MR, Kester AD, Schep G: High-intensity strength training improves quality of life in cancer survivors. Acta Oncol 2007;46: 1143-1151.

-45 Stefanelli F, Meoli I, Cobuccio R, Curcio C, Amore D, Casazza D, Tracey M, Rocco G: High-intensity training and cardiopulmonary exercise testing in patients with chronic obstructive pulmonary disease and nonsmall-cell lung cancer undergoing lobectomy. Eur J Cardiothorac Surg 2013;44:e260-e265.

46 Myers J, Gademan M, Brunner K, Kottman W, Boesch C, Dubach P: Effects of high-intensity training on indices of ventilatory efficiency in chronic heart failure. J Cardiopulm Rehabil Prev 2012;32:9-16.

47 Weston M, Weston KL, Prentis JM, Snowden CP: High-intensity interval training (HIT) for effective and time-efficient pre-surgical exercise interventions. Perioper Med (Lond) 2016;5:2.

48 Vermeulen KM, Post WJ, Span MM, van der Bij W, Koëter GH, TenVergert EM: Incomplete quality of life data in lung transplant research: comparing cross sectional, repeated measures ANOVA, and multi-level analysis. Respir Res 2005;6:101.
Exercise Training in Cancer Patients for Elective Gastrointestinal Surger
Dig Surg 2016;33:439-447 DOI: $10.1159 / 000445958$ 